\title{
Effect of $0.9 \%$ saline in 5\% dextrose, Plasma-Lyte 148 and Isolyte-P used as intravenous maintenance fluids on the electrolyte status of non-critically ill hospitalised children: Results of a prospective randomised open label study
}

\author{
Balaji Chinnasami ${ }^{1}$, *Pulim Manoj Kumar Reddy ${ }^{2}$, R Dhinakaran ${ }^{3}$, M S K M Chaitanya ${ }^{4}$, Vijayakrishnan \\ $\mathbf{G}^{5}$
}

Sri Lanka Journal of Child Health, 2022; 51(1): 111-118

DOI: http://dx.doi.org/10.4038/sljch.v51i1.10008

\begin{abstract}
Background: Consensus regarding the correct type of maintenance intravenous (IV) fluid in noncritically ill stable children is yet to be reached. Most previous studies are based on children admitted in intensive care units (ICUs) or post-operative wards.
\end{abstract}

Objectives: To compare the effects of three different IV fluids, namely $0.18 \%$ saline in $5 \%$ dextrose (Isolyte-P), $0.9 \%$ saline in $5 \%$ dextrose (DNS) and Plasma-Lyte 148 on the change in electrolyte levels in stable children admitted in a general ward after giving them maintenance fluids for 48 hours.

Method: Our study was a non-blinded, randomised pragmatic trial conducted at the paediatric general ward of the SRM Medical College and Hospital, Kattankulathur, South India from June 2018 to March 2019. Eligible children $(n=212)$ were between 3 months to 12 years old, requiring hospitalisation due to their illness and needing IV maintenance fluids for a minimum of 48 hours.

${ }^{1}$ Professor Department of Paediatrics, SRM Medical College Hospital and Research Centre, SRM Institute of Science and Technology, Potheri, Kattankulathur, Tamil Nadu, India, ${ }^{2}$ Assistant Professor, Department of Paediatrics, Konaseema Institute of Medical Sciences and Research Foundation, Amalapuram, Andhra Pradesh, India, ${ }^{3}$ Assistant Professor, SRM Medical College Hospital and Research Centre, SRM Institute of Science and Technology, Potheri, Kattankulathur, Tamil Nadu, India, ${ }^{4}$ Pharm D, SRM College of Pharmacy, SRM Institute of Science and Technology, Potheri, Kattankulathur, Tamil Nadu, India, ${ }^{5}$ Associate Professor Department of Community Medicine, SRM Medical College Hospital and Research Centre, SRM Institute of Science and Technology, Potheri, Kattankulathur, Tamil Nadu, India,

*Correspondence: dr.manojkumar.34@gmail.com

https://orcid.org/ 0000-0001-6863-3179

(Received on 13 June 2021: Accepted after revision on 24 August 2021)

The authors declare that there are no conflicts of interest

Study was funded by SRM hospital.

Open Access Article published under the Creative

Commons Attribution CC-BY (c) (i) License
Children requiring ICU admissions, children needing postoperative care, children with dyselectrolytaemia and children on drugs or suffering from diseases that altered plasma sodium levels were not included in the study.

Intervention: Enrolled children, using computer generated codes, were randomised equally (50 in each group) to groups receiving Isolyte $\mathrm{P}, \mathrm{DNS}$ or Plasma-Lyte148 as IV fluids for a minimum of 48 hours.

Main outcomes and measures: Main outcome was difference in change in sodium among the three IV fluids after 48 hours of giving them as maintenance fluids. Secondary outcomes were to find the difference in other biochemical parameters like urea, creatinine, potassium, chloride and bicarbonate at the same endpoint.

Statistical analysis: Pre- and post-values of biochemical parameters were tested for significance using paired sample t-test. Comparison of the three fluid groups was done by ANOVA.

Results: After 48 hours, the serum sodium levels in DNS, Isolyte-P and Plasma-Lyte148 groups had increased on an average by $0.48 \mathrm{meq} / \mathrm{L}, 0.8 \mathrm{meq} / \mathrm{L}$ and $0.64 \mathrm{meq} / \mathrm{L}$ respectively from the baseline and the difference was not statistically significant $(\mathrm{p}=$ 0.854 ). Mean change in potassium values were $0.142 \mathrm{meq} / \mathrm{L}, 0.188 \mathrm{meq} / \mathrm{L}$ and $0.230 \mathrm{meq} / \mathrm{L}$ in DNS, Isolyte-P and Plasma-lyte148 respectively. There was a significant difference in potassium among the fluids as potassium fell in DNS group ( $p$ $=0.001)$. Urea, creatinine and bicarbonate levels improved in all three groups. There were no clinically observable adverse events due to dyselectrolytaemia among the three groups.

Conclusions: There was no significant change in sodium after giving any of the three fluids Isolyte-P, DNS or Plasma-Lyte 148 in children who were clinically stable.

(Keywords: Hyponatraemia, Intravenous fluids, Normal saline, Parenteral fluid therapy, Isolyte-P, Plasma-Lyte 148). 


\section{Introduction}

Majority of children getting admitted in hospital require parenteral fluids. Choice of intravenous (IV) fluid for children has continued to evolve till date. Initially, $0.18 \%$ saline in $5 \%$ dextrose (Isolyte-P) was commonly used as maintenance fluid ${ }^{1,2}$. However, there were concerns of hospital-acquired hyponatraemia related to hypotonic IV fluid administration $^{3-12}$. Moritz ML, et al ${ }^{13}$ introduced the use of $0.9 \%$ saline as maintenance parenteral fluid to prevent hospital-acquired hyponatraemia in children. The American Academy of Pediatrics recommends administering isotonic fluids for all paediatric age groups from 1 month to 18 years of age $^{14}$. Several previously published Randomised Control Trials (RCTs), systematic reviews and metanalyses have consistently found that use of isotonic solutions decrease the risk of hyponatraemia ${ }^{6,15,16}$. However, the choice of isotonic fluid is still not clear. Excessive use of saline was shown to cause hyperchloraemic acidosis ${ }^{17}$. British consensus guidelines on IV fluid therapy for adult surgical patients clearly recommends use of balanced crystalloids in preference to saline ${ }^{18}$. In the article 'The great fluid debate' Santi M, et al suggested that 'balanced' salt crystalloids should be preferred for volume resuscitation and maintenance in paediatric patients ${ }^{19}$. Further, as per systematic review by Foster BA, et al, evidence of risk of hyponatremia in hypotonic fluids is based on studies in intensive care and postoperative settings ${ }^{6}$. For children admitted in general wards, studies are insufficient to recommend against hypotonic fluids. We conducted this study to add evidence about the influence of IV fluids on electrolyte levels in non-critically ill children.

\section{Objective}

To study the effects of three different IV fluid regimens, namely, Isolyte-P, $0.9 \%$ saline in $5 \%$ dextrose (DNS) and Plasma-Lyte 148 on the change in electrolyte levels in hospitalised non-critically ill children admitted in a general ward.

\section{Hypothesis}

We planned to conduct a non-inferiority trial. We hypothesized that there will be no significant difference in change in sodium levels after 48 hours of giving the three IV fluid regimen in non-critically ill children.

\section{Method}

A prospective RCT was carried out from June 2018 to March 2019 in children 3 months to 12 years old admitted to our 120-bedded paediatric general ward in SRM Medical College and Hospital, Kattankulathur, Tamil Nadu, India. Patients considered to need IV maintenance fluids for a minimum of 48 hours by the treating physician were included in the study. We recruited non-critically ill children admitted in a general paediatric ward.

Children requiring intensive care unit (ICU) admission like respiratory distress, shock or failure of other organs were not included in the study. Postoperative cases were also not included in the study. Children who received fluids in the last 24 hours, or had hyponatraemia (plasma sodium $<132 \mathrm{mEq} / \mathrm{L}$ ), hypernatraemia (plasma sodium $>148 \mathrm{mEq} / \mathrm{L}$ ) or hyperglycaemia (blood glucose $>180 \mathrm{mg} / \mathrm{dL}$ ), dehydration, severe acute malnutrition (weight-forlength/height $<-3 \mathrm{SD}$ ), cirrhosis of the liver, congestive heart failure, acute or chronic renal failure or nephrotic syndrome were also excluded. Children receiving drugs that altered plasma sodium levels, like frusemide, hydrochlorothiazide, vasopressin and mannitol were not included in the study.

Block randomization with equal allocation ratios for the three groups was done with randomly permuted blocks of variable sizes using www.randomisation.com, and a randomization sequence was generated. The sequence was converted to numbered envelopes by a person not directly involved in the study. Concealment was done by making 150 sealed opaque envelopes containing 50 lots of each group. This was an open label study and after randomisation the treating physician was informed that a particular patient had been randomised to one of the three fluid regimen. However subjects continued to receive treatment for their primary disease, as determined by the physician.

Eligible children at the time of admission, and before treatment was started, were randomized into three IV fluid groups: Group A, Isolyte P, Group B, Plasma-Lyte 148 and Group C, DNS. All three groups received the respective fluids for 48 hours or more depending upon the patient's condition at standard maintenance rates which were calculated according to child's weight using the Holliday Segar formula ${ }^{20}$.

Baseline demographic details were recorded at enrolment. We monitored clinically for features of fluid overload or dehydration and neurological features including encephalopathy throughout the study period. We measured the plasma electrolytes sodium, potassium, chloride and the biochemical parameters bicarbonate, urea and creatinine on admission, before starting IV fluids, and after 48 hours of continuing IV fluids.

The primary outcome was the difference in change in sodium among the three IV fluids after 48 hours of giving them as maintenance fluids. Secondary outcome included the difference in change in other 
electrolytes potassium, chloride, bicarbonate and biochemical parameters urea and creatinine after the same 48 hours end point. We also looked for any adverse events like dehydration, shock, overhydration or neurological symptoms like seizures, headache and encephalopathy. Fluids were restricted if child developed signs of over-hydration during the trial. Extra fluids were given if signs of dehydration or shock developed during the trial.

Sample size: As suggested by Yung M, et al, previous studies suggest a mean fall in sodium by $3.1 \mathrm{meq} / 1$ with standard deviation of $4.41 \mathrm{meq} / \mathrm{L}$ after giving IV fluids ${ }^{3}$. We estimated a minimum sample size of 34 per group to detect a difference of $3 \mathrm{meq} / \mathrm{L}$ with an alpha of 0.05 and $80 \%$ power. However, since we also intended to assess change in other electrolytes as secondary outcomes, we took more subjects i.e. 50 in each group.

Ethical issues: The study protocol was approved by the Institutional Ethics Committee of SRM Medical College Hospital and Research Centre, Chennai,
India (No. 692/IEC/2014). Being a RCT, the study was registered at www.Ctri.nic.in. (Clinical Trial Registry No. CTRI/2018/05/014231). Written informed consent was obtained from the parent or guardian of all children included in the study before enrolment. Financial support was provided for the study by the hospital.

Statistical analysis: Biochemical parameters are presented as mean and standard deviation. Baseline values among the three fluid groups were compared using ANOVA. Pre- and post-intervention values of biochemical parameters in each group were tested for significance by the paired sample t-test. Difference in change in biochemical parameters among the three groups were also analysed by ANOVA.

\section{Results}

Of the 635 consecutive children screened, 212 fulfilled the inclusion criteria. Of the 212, 62 fulfilled at least one exclusion criterion. One hundred and fifty children were randomized equally to the three groups (Figure 1).

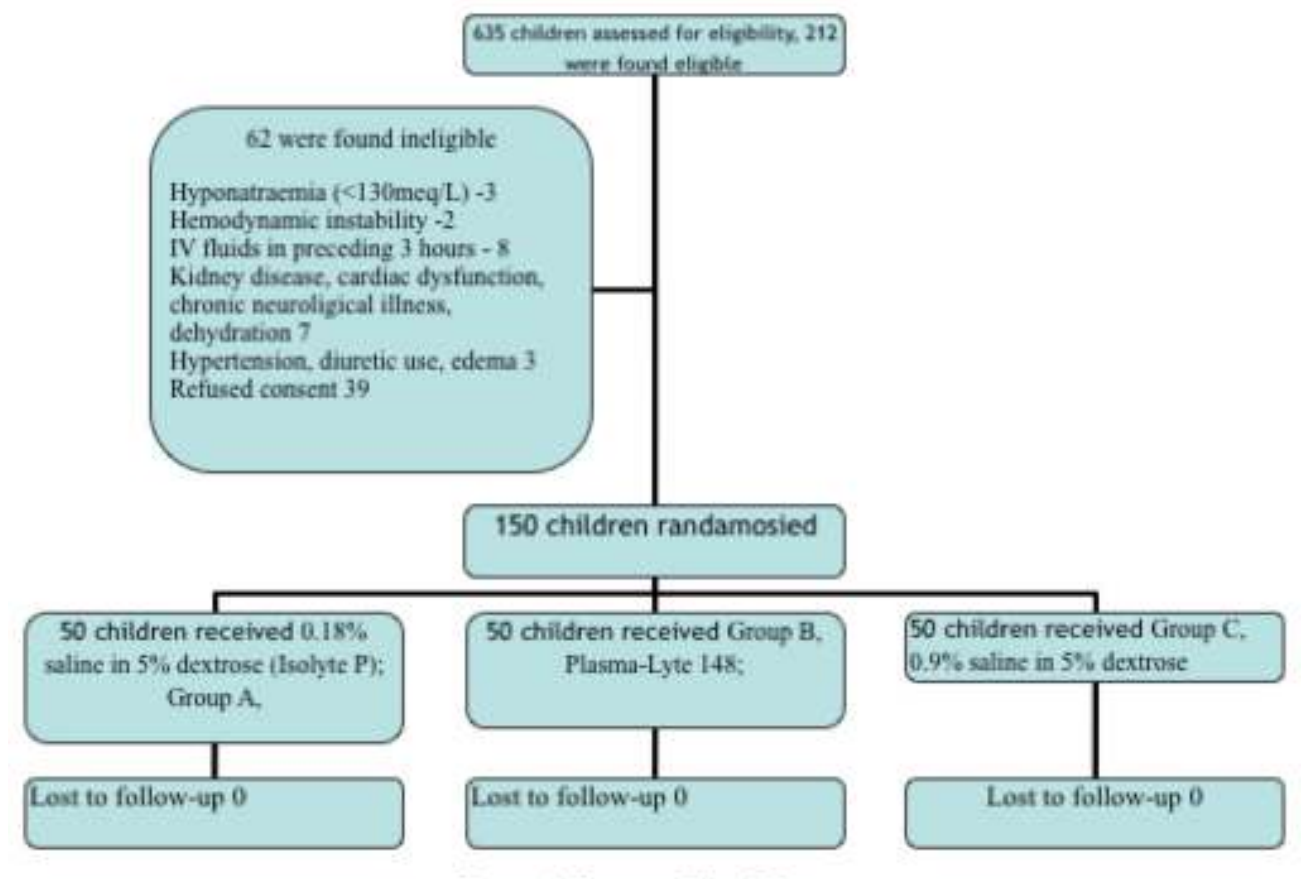

Figure 1 Consort Flow Diagram

The mean age of the study population was $54.11 \pm$ 48.38 months. Most of the children in all three groups were between two to three years of age. The male: female ratio was $1.42: 1$. The mean weight of the study population was $16.18 \pm 10.73 \mathrm{~kg}$. All three groups received comparable amount of fluids. The major diagnoses at admission were acute respiratory tract infections (bronchiolitis, wheeze associated lower respiratory infection and pneumonia), pain in abdomen, malaria, enteric fever, acute viral hepatitis and seizure disorder. There was no loss to follow up in any of the groups. The baseline characteristics of the three group are shown in Table 1.

Age distribution was similar in all three groups. Baseline parameters like potassium, bicarbonate, urea and creatinine were similar. Baseline sodium and chloride levels were significantly different in group $\mathrm{C}$ but this was not of major concern since we compared the change in electrolyte levels after 48 hours and not the absolute electrolyte levels at 48 hours. 
Table 1: Baseline characteristics $(n=150)$

\begin{tabular}{|c|c|c|c|c|}
\hline Patient characteristics & $\begin{array}{c}\text { Group A }(n=50) \\
\text { Isolyte P }\end{array}$ & $\begin{array}{l}\text { Group B }(n=50) \\
\text { Plasma-Lyte } 148\end{array}$ & $\begin{array}{c}\text { Group C }(n=50) \\
\text { DNS }\end{array}$ & p-value \\
\hline Age in months Mean $\pm \mathrm{SD}$ & $46.51 \pm 49.47$ & $61.28 \pm 48.39$ & $53.86 \pm 47.20$ & 0.314 \\
\hline Sex Male: Female ratio & 1.83 & 1.08 & 1.38 & \\
\hline $\begin{array}{l}\text { Mean fluid administered in } 48 \mathrm{hrs} \\
(\mathrm{ml} / \mathrm{kg}) \text { Mean } \pm \mathrm{SD}\end{array}$ & $172.94 \pm 36.96$ & $163.80 \pm 34.25$ & $169.07 \pm 37.41$ & 0.451 \\
\hline $\begin{array}{l}\text { Biochemical parameters, Mean } \pm \text { SD } \\
\text { Serum sodium, meq/L } \\
\text { Serum potassium, meq/L } \\
\text { Serum chloride, meq/L } \\
\text { Serum bicarbonate, meq/L } \\
\text { Serum urea, } \mathrm{mg} / \mathrm{dl} \\
\text { Serum creatinine, } \mathrm{mg} / \mathrm{dl}\end{array}$ & $\begin{array}{c}137.54 \pm 4.590 \\
4.320 \pm 0.5295 \\
102.54 \pm 4.970 \\
18.24 \pm 3.761 \\
21.08 \pm 8.962 \\
0.505 \pm 0.1317\end{array}$ & $\begin{array}{c}137.86 \pm 4.408 \\
4.104 \pm 0.3812 \\
102.82 \pm 4.918 \\
18.90 \pm 3.688 \\
19.64 \pm 6.748 \\
0.538 \pm 0.1354\end{array}$ & $\begin{array}{c}141.42 \pm 3.447 \\
4.268 \pm 0.5916 \\
105.36 \pm 3.800 \\
17.50 \pm 4.296 \\
20.68 \pm 6.982 \\
0.530 \pm 0.1329\end{array}$ & $\begin{array}{l}0.00^{*} \\
0.089 \\
0.004^{*} \\
0.207 \\
0.623 \\
0.436\end{array}$ \\
\hline $\begin{array}{l}\text { Diagnosis at admission, Number } \\
\text { WALRI } \\
\text { Bronchiolitis } \\
\text { Acute hepatitis } \\
\text { Pneumonia } \\
\text { Seizure } \\
\text { Enteric fever } \\
\text { Gastritis / pain in abdomen } \\
\text { Malaria }\end{array}$ & $\begin{array}{l}17 \\
04 \\
05 \\
10 \\
02 \\
01 \\
07 \\
04\end{array}$ & $\begin{array}{l}14 \\
07 \\
03 \\
12 \\
03 \\
02 \\
07 \\
02\end{array}$ & $\begin{array}{l}15 \\
06 \\
03 \\
08 \\
04 \\
02 \\
09 \\
03\end{array}$ & \\
\hline
\end{tabular}

WALRI: Wheeze associated lower respiratory infection

All patients who entered the study received IV fluids for 48 hours. Fluid restriction or extra fluids were not needed in children of all three groups. Values of the biochemical parameters before and after intervention are presented as tables 2, 3 and 4 .

Table 2: Comparison of electrolyte values in Isolyte P group

\begin{tabular}{|l|c|c|c|}
\hline \multicolumn{1}{|c|}{ Biochemical parameter } & $\begin{array}{c}\text { Before intervention } \\
\text { Mean } \pm \text { SD }\end{array}$ & $\begin{array}{c}\text { After intervention } \\
\text { Mean } \pm \text { SD }\end{array}$ & p value $^{\#}$ \\
\hline Serum sodium, meq/L & $137.54 \pm 4.590$ & $138.34 \pm 3.378$ & 0.082 \\
\hline Serum potassium, meq/L & $4.320 \pm 0.5295$ & $4.506 \pm 0.5644$ & $0.039^{*}$ \\
\hline Serum chloride, $\mathrm{meq} / \mathrm{L}$ & $102.54 \pm 4.970$ & $102.50 \pm 4.564$ & 0.942 \\
\hline Serum bicarbonate, $\mathrm{meq} / \mathrm{L}$ & $18.24 \pm 3.761$ & $19.50 \pm 3.940$ & $0.025^{*}$ \\
\hline Serum urea, $\mathrm{mg} / \mathrm{dl}$ & $21.08 \pm 8.962$ & $18.34 \pm 8.270$ & $0.006^{*}$ \\
\hline Serum creatinine, $\mathrm{mg} / \mathrm{dl}$ & $0.506 \pm 0.132$ & $0.482 \pm 0.1521$ & 0.4015 \\
\hline
\end{tabular}

\#Paired sample t-test, ${ }^{*} p<0.05$ significant

The Isolyte $\mathrm{P}$ group demonstrated a statistically significant rise in bicarbonate and potassium values with $\mathrm{p}$ values 0.025 and 0.039 respectively (Table 2). However, for medical purposes clinically significant change for potassium is taken as
$0.7 \mathrm{meq} / \mathrm{L}$. Hence there was no clinically significant change in either potassium or bicarbonate values after giving Isolyte $\mathrm{P}$. The sodium and chloride values remained the same without much change.

Table 3: Comparison of electrolyte values in Plasma-Lyte 148 group

\begin{tabular}{|l|c|c|c|}
\hline \multicolumn{1}{|c|}{ Biochemical parameter } & $\begin{array}{c}\text { Before intervention } \\
\text { Mean } \pm \text { SD }\end{array}$ & $\begin{array}{c}\text { After intervention } \\
\text { Mean } \pm \text { SD }\end{array}$ & p value $^{\#}$ \\
\hline Serum sodium, meq/L & $137.86 \pm 4.408$ & $138.50 \pm 3.776$ & 0.103 \\
\hline Serum potassium, meq/L & $4.104 \pm 0.3812$ & $4.334 \pm 0.4479$ & $0.000^{*}$ \\
\hline Serum chloride, $\mathrm{meq} / \mathrm{L}$ & $102.82 \pm 4.918$ & $103.38 \pm 4.184$ & 0.260 \\
\hline Serum bicarbonate, $\mathrm{meq} / \mathrm{L}$ & $18.90 \pm 3.688$ & $19.46 \pm 3.715$ & 0.299 \\
\hline Serum urea, $\mathrm{mg} / \mathrm{dl}$ & $19.64 \pm 6.748$ & $13.28 \pm 4.777$ & $0.000^{*}$ \\
\hline Serum creatinine, $\mathrm{mg} / \mathrm{dl}$ & $0.538 \pm 0.1354$ & $0.488 \pm 0.1023$ & $0.003^{*}$ \\
\hline
\end{tabular}

\# Paired sample t-test, ${ }^{*} p<0.05$ significant

The Plasma-Lyte 148 group had a significant increase in potassium value $(\mathrm{p}=0.000)$ (Table 3$)$. However, considering the medically significant change of potassium as $0.7 \mathrm{meq} / \mathrm{L}$, the changes in potassium values were not clinically significant. The changes in other electrolytes sodium, chloride and bicarbonate were not statistically or clinically significant. 
Table 4: Comparison of electrolyte values in DNS group

\begin{tabular}{|l|c|c|c|}
\hline \multicolumn{1}{|c|}{ Biochemical parameter } & $\begin{array}{c}\text { Before intervention } \\
\text { Mean } \pm \text { SD }\end{array}$ & $\begin{array}{c}\text { After intervention } \\
\text { Mean } \pm \text { SD }\end{array}$ & p value $^{\#}$ \\
\hline Serum sodium, meq/L & $141.42 \pm 3.447$ & $141.90 \pm 2.830$ & 0.292 \\
\hline Serum potassium, meq/L & $4.268 \pm 0.5916$ & $4.126 \pm 0.5872$ & 0.094 \\
\hline Serum chloride, $\mathrm{meq} / \mathrm{L}$ & $105.36 \pm 3.800$ & $106.36 \pm 2.940$ & $0.045^{*}$ \\
\hline Serum bicarbonate, $\mathrm{meq} / \mathrm{L}$ & $17.50 \pm 4.296$ & $20.26 \pm 3.573$ & $0.000^{*}$ \\
\hline Serum urea, $\mathrm{mg} / \mathrm{dl}$ & $20.68 \pm 6.982$ & $16.12 \pm 6.617$ & $0.000^{*}$ \\
\hline Serum creatinine, $\mathrm{mg} / \mathrm{dl}$ & $0.530 \pm 0.1329$ & $0.482 \pm 0.1521$ & $0.007^{*}$ \\
\hline
\end{tabular}

\# Paired sample t-test, ${ }^{*} p<0.05$ significant

There was a significant increase in the bicarbonate value but there were no significant changes in the sodium and potassium in those patients who received DNS (Table 4). Even though the chloride values were significantly higher after administration of DNS fluid, considering the clinically significant change in chloride value of $4 \mathrm{meq} / \mathrm{L}$, the mean difference in chloride value after giving DNS (1 meq/L) was very meagre (Table 4 ).
Urea and creatinine levels improved in all three groups although creatinine levels did not improve significantly in the Isolyte $\mathrm{P}$ group. Overall there was no significant change in sodium value after the administration of fluids in all 3 groups as evidenced by the paired t-test (Tables 2, 3 and 4). After 48 hours, the serum sodium levels in groups A, B and $\mathrm{C}$ had increased by $0.8 \mathrm{mmol} / \mathrm{L}, 0.64 \mathrm{mmol} / \mathrm{L}$ and $0.48 \mathrm{mmol} / \mathrm{L}$ respectively from the baseline, but none of these rises were statistically significant $(\mathrm{p}>0.05)$.

Table 5: Changes in mean electrolyte concentrations for the three intravenous fluids

\begin{tabular}{|l|c|c|c|c|}
\hline \multicolumn{1}{|c|}{ Parameter } & DNS (n=50) & $\begin{array}{c}\text { Isolyte-P } \\
\mathbf{( n = 5 0 )}\end{array}$ & $\begin{array}{c}\text { Plasma-Lyte 148 } \\
\mathbf{( n = 5 0 )}\end{array}$ & p value \\
\hline Sodium (meq/L) Mean \pm SD & $0.48 \pm 3.19$ & $0.82 \pm 3.16$ & $0.64 \pm 2.72$ & 0.854 \\
\hline Potassium (meq/L) Mean \pm SD & $-0.142 \pm 0.588$ & $0.188 \pm 0.613$ & $0.230 \pm 0.401$ & $0.001^{*}$ \\
& & & & $\begin{array}{l}0.008^{*} \text { (DNS vs Iso P) } \\
0.002^{*} \text { (DNS vs Plasma-Lyte) } \\
0.920 \text { (Iso P vs Plasma-Lyte) }\end{array}$ \\
\hline Chloride (meq/L) Mean \pm SD & & & & 0.366 \\
\hline Bicarbonate (mmol/L) Mean \pm SD & $2.76 \pm 3.61$ & $1.27 \pm 3.81$ & $0.56 \pm 3.77$ & $0.012^{*}$ \\
& & & & 0.117 (DNS vs Iso P) \\
& & & & $0.010^{*}$ (DNS vs Plasma-Lyte) \\
& & $-2.63 \pm 6.74$ & $-6.32 \pm 6.89$ & 0.609 (Iso P vs Plasma-Lyte) \\
\hline Urea (mg/dl) Mean \pm SD & $-4.56 \pm 7.82$ & & & $0.039^{*}$ \\
& & & & 0.371 (DNS vs Iso P) \\
& & & & 0.438 (DNS vs Plasma-Lyte) \\
& & & $0.030^{*}$ (Iso P vs Plasma-Lyte \\
\hline Creatinine (mg/dl) Mean \pm SD & $-0.048 \pm 0.122$ & $-0.0129 \pm 0.0789$ & $-0.054 \pm 0.107$ & 0.107 \\
\hline
\end{tabular}

DNS: $0.9 \%$ saline in $5 \%$ dextrose

Change in sodium, chloride and creatinine concentrations after 48 hours of fluids was similar among the three fluids. Change in potassium was significantly different due to the DNS group where it decreased while it increased in other two fluids. Also change in urea and bicarbonate was not the same among the three fluids.

There were no clinically observable adverse events like seizures, drowsiness, facial puffiness or dehydration among the three groups.

We did not do statistical comparison of the three groups with regards to occurrence of electrolyte disorders like hyponatremia or hypokalaemia since our study sample size was not adequately powered.

\section{Discussion}

The primary aim of the study was to investigate if there is a difference in change in sodium levels after giving the three IV fluids. As hypothesised we found no difference among the fluids with regards to change in sodium in paediatric patients less than 12 years of age. None of the three fluid types resulted in significant change in sodium after 48 hours of fluids. In contrast, many studies and meta-analyses have favoured the use of isotonic fluids instead of hypotonic fluids in view of decrease in sodium levels after giving hypotonic fluids ${ }^{3-11}$. This contradiction is probably because most previous studies included subjects mainly from intensive care units (ICUs) and critically ill patients. In such patients the influence of the Syndrome of Inappropriate Antidiuretic Hormone (SIADH) on serum sodium levels is high. Our study population were not critically ill and were relatively stable and were admitted to a general ward rather than an ICU. Hence the influence of SIADH should be less and also the renal function should be intact to promptly correct the imbalance caused by IV fluids. 
Supporting our study Friedman JN, et al in his comparative study of isotonic and hypotonic IV fluids among 110 children admitted in a general ward found that the mean serum sodium levels after 48 hours of giving the two fluids was not significantly different ${ }^{12}$. Omoifo CE, et al in his study of 65 healthy children posted for minor elective surgeries received Normal saline, Ringer lactate or Isolate P and found similar serum sodium levels after giving the fluids ${ }^{21}$. Kumar M, et al in his study of isotonic vs hypotonic saline given as maintenance IV fluid in stable children admitted in paediatric wards found similar effects on sodium imbalance ${ }^{22}$.

Apart from sodium our study also compared the effects of the three IV fluids on other electrolytes like potassium, chloride and bicarbonate. The electrolyte composition of the fluids influenced the child's serum electrolytes. For example potassium fell in the DNS group as it lacks potassium and increased in other two groups. This resulted in significant difference in change in potassium among the fluids (Table 5). Similar to other studies, DNS containing $154 \mathrm{meq} / \mathrm{L}$ of chloride showed a significant increase in the chloride level ${ }^{23-28}$. These changes in electrolyte levels were not clinically significant. Children in all three groups had higher urea, creatinine and lower bicarbonate levels at baseline suggesting subclinical dehydration due to decreased oral intake during illness which improved in all three groups.

One limitation of the study was that the 3 groups were not comparable in terms of baseline serum sodium and chloride values. According to Harvey LA there can be one or two baseline parameters with significant difference when multiple variables are considered $^{29}$. Initially, the study was planned to compare the incidence of hyponatremia among the three fluids in stable children. But the incidence of hyponatremia in stable children is less and the sample size needed would have been large. Hence due to feasibility reasons we compared the change in electrolyte levels and not absolute values. The other limitations were not measuring oral fluid intake, urine output and weight after fluid therapy as a measure of fluid overload, and non-estimation of serum antidiuretic hormone levels and urine osmolality. Also our study was an open labelled study and blinding would have avoided potential biases.

The findings have major implications in the choice of our fluids for stable non-critically ill children. At present there are very few studies looking at sodium levels in non-operative and non-ICU patients. Our study adds to the evidence that there is no significant change in sodium after giving any of the three IV fluids Isolyte P, DNS and Plasma-Lyte 148 in children who are not severely ill and admitted in a general ward. Further studies with adequate sample size are needed to compare the incidence of hyponatremia and hypokalemia among these fluids in stable children.

\section{Conclusion}

As hypothesised, there was no significant change in sodium after giving any of the three IV Isolyte-P, DNS or Plasma-Lyte 148 in children under 12 years of age who were clinically stable.

\section{References}

1. Siegel NJ. Fluids, electrolytes and acidbase. In: Rudolph's Pediatrics, $21^{\text {st }}$ edition. New York: McGraw Hill, 2003.

2. Greenbaum LA. Pathophysiology of body fluids and fluid therapy. In: Nelson's Textbook of Pediatrics, 20 $0^{\text {th }}$ ed. Philadelphia: Elsevier Science, 2016: 34691.

3. Yung M, Keeley S. Randomised controlled trial of intravenous maintenance fluids. Journal of Paediatrics and Child Health 2009; 45(1-2): 9-14.

https://doi.org/10.1111/j.14401754.2007.0 1254.x

4. Kannan L, Lodha R, Vivekanandhan S, Bagga A, Kabra SK, Kabra M. Intravenous fluid regimen and hyponatraemia among children: a randomized controlled trial. Pediatric Nephrology 2010; 25(11): 23039. https://doi.org/10.1007/s00467-010-16004

5. Rey C, Los-Arcos M, Hernández A, Sánchez A, Díaz JJ, López-Herce J. Hypotonic versus isotonic maintenance fluids in critically ill children: a multicenter prospective randomized study. Acta Paediatrica 2011; 100(8): 1138-43. https://doi.org/10.1111/j.16512227.2011.0 2209.x

6. Foster BA, Tom D, Hill V. Hypotonic versus isotonic fluids in hospitalized children: a systematic review and metaanalysis. Journal of Pediatrics 2014; 165(1): 163-9. https://doi.org/10.1016/j.jpeds.2014.01.04 0

7. Saba TG, Fairbairn J, Houghton F, Laforte D, Foster BJ. A randomized controlled trial 
of isotonic versus hypotonic maintenance intravenous fluids in hospitalized children. BMC Pediatrics 2011; 11(1): 82.

https://doi.org/10.1186/1471-2431-11-82

8. McNab S, Duke T, South M, Babl FE, Lee $\mathrm{KJ}$, Arnup SJ, et al. $140 \mathrm{mmol} / \mathrm{L}$ of sodium versus $77 \mathrm{mmol} / \mathrm{L}$ of sodium in maintenance intravenous fluid therapy for children in hospital (PIMS): a randomised controlled double-blind trial. Lancet 2015; 385(9974): 1190-7.

https://doi.org/10.1016/S01406736(14)614 59-8

9. Shamim A, Afzal K, Ali SM. Safety and efficacy of isotonic $(0.9 \%)$ vs. hypotonic $(0.18 \%)$ saline as maintenance intravenous fluids in children: a randomized controlled trial. Indian Pediatrics 2014; 51(12): 96974.

https://doi.org/10.1007/s13312-014-05425

10. Pemde HK, Dutta AK, Sodani R, Mishra K. Isotonic intravenous maintenance fluid reduces hospital acquired hyponatremia in young children with central nervous system infections. Indian Journal of Pediatrics 2015; 82(1): 13-8. https://doi.org/10.1007/s12098-014-14361

11. Ramanathan S, Kumar P, Mishra K, Dutta AK. Isotonic versus hypotonic parenteral maintenance fluids in very severe pneumonia. Indian Journal of Pediatrics 2016; 83(1): 27-32. https://doi.org/10.1007/s12098-015-17916

12. Friedman JN, Beck CE, DeGroot J, Geary DF, Sklansky DJ, Freedman SB. Comparison of isotonic and hypotonic intravenous maintenance fluids: a randomized clinical trial. JAMA Pediatrics 2015; 169(5): 445-51.

https://doi.org/10.1001/jamapediatrics.201 4.3809

13. Moritz ML, Ayus JC. Prevention of hospital-acquired hyponatraemia: a case for using isotonic saline. Pediatrics 2003; 111: 227-30. https://doi.org/10.1542/peds.111.2.227

14. Feld LG, Neuspiel DR, Foster BA, Leu MG, Garber MD, Austin K, et al. Clinical practice guideline: maintenance intravenous fluids in children. Pediatrics 2018; 142(6): e20183083.

https://doi.org/10.1542/peds.2018-3083

15. Wang J, Xu E, Xiao Y. Isotonic versus hypotonic maintenance IV fluids in hospitalized children: a meta-analysis. Pediatrics 2014; 133(1): 105-13. https://doi.org/10.1542/peds.2013-2041

16. Yang G, Jiang W, Wang X, Liu W. The efficacy of isotonic and hypotonic intravenous maintenance fluid for paediatric patients: a meta-analysis of randomized controlled trials. Pediatric Emergency Care 2015; 31(2): 122-6. https://doi.org/10.1097/PEC.00000000000 00352

17. Morgan T. The ideal crystalloid: What is 'balanced'? Current Opinion in Critical Care 2013; 19: 299-307. https://doi.org/10.1097/MCC.0b013e3283 $632 \mathrm{~d} 46$

18. Soni N. British Consensus Guidelines on intravenous fluid therapy for adult surgical patients (GIFTASUP): Cassandra's view. Anaesthesia 2009; 64(3): 235. https://doi.org/10.1111/j.13652044.2009.0 5886_1.x

19. Santi M, Lava SA, Camozzi P, Giannini O, Milani GP, Simonetti GD, et al. The great fluid debate: saline or so-called "balanced" salt solutions? Italian Journal of Pediatrics 2015; 41(1): 1-5. https://doi.org/10.1186/s13052-015-01542

20. Holliday MA, Friedman AL, Segar WE, Chesney R, Finberg L. Acute hospitalinduced hyponatraemia in children: a physiologic approach. Journal of Pediatrics 2004; 145(5): 584-7. https://doi.org/10.1016/j.jpeds.2004.06.07 7

21. Omoifo CE, Edomwonyi NP, Idogun SE. Incidence of hyponatraemia following the use of three different intravenous fluids in paediatric surgery. African Journal of Paediatric Surgery 2018; 15(2): 69. https://doi.org/10.4103/ajps.AJPS_40_16

22. Kumar M, Mitra K, Jain R. Isotonic versus hypotonic saline as maintenance intravenous fluid therapy in children under 5 years of age admitted to general paediatric wards: a randomised controlled 
trial. Paediatrics and International Child Health 2020; 40(1): 44-9.

https://doi.org/10.1080/20469047.2019.16 19059

23. Makoff DL, da Silva JA, Rosenbaum BJ, Levy SE, Maxwell MH. Hypertonic expansion: acid-base and electrolyte changes. American Journal of PhysiologyLegacy Content 1970; 218(4): 1201-7. https://doi.org/10.1152/ajplegacy.1970.21 8.4.1201

24. Lobo DN. Intravenous $0.9 \%$ saline and general surgical patients: a problem, not a solution. Annals of Surgery 2012; 255: 830-2.

https://doi.org/10.1097/SLA.0b013e31825 $0766 \mathrm{c}$

25. Phillips CR, Vinecore K, Hagg DS, Sawai $\mathrm{RS}$, Differding JA, Watters JM, et al. Resuscitation of haemorrhagic shock with normal saline vs. lactated Ringer's: effects on oxygenation, extravascular lung water and haemodynamics. Critical Care 2009; 13(2): R30.

https://doi.org/10.1186/cc7736

26. Williams EL, Hildebrand KL, McCormick SA, Bedel MJ. The effect of intravenous lactated Ringer's solution versus $0.9 \%$ sodium chloride solution on serum osmolality in human volunteers. Anesthesia \& Analgesia 1999; 88(5): 9991003.

https://doi.org/10.1097/000005391999050 00-00006
27. Waters JH, Gottlieb A, Schoenwald P, Popovich MJ, Sprung J, Nelson DR. Normal saline versus lactated Ringer's solution for intraoperative fluid management in patients undergoing abdominal aortic aneurysm repair: an outcome study. Anesthesia \& Analgesia 2001; 93(4): 817-22.

https://doi.org/10.1097/000005392001100 00-00004

28. Wilkes NJ, Woolf R, Mutch M, Mallett SV, Peachey T, Stephens R, et al. The effects of balanced versus saline-based hetastarch and crystalloid solutions on acid-base and electrolyte status and gastric mucosal perfusion in elderly surgical patients. Anesthesia \& Analgesia 2001; 93(4): 8116.

https://doi.org/10.1097/000005392001100 00-00003

29. Harvey LA. Statistical testing for baseline differences between randomised groups is not meaningful. Spinal Cord 2018; 56: 919. https://doi.org/10.1038/s41393-018-0203$\mathrm{y}$ 